\title{
Identification of Cropping Pattern in Khadambe bk. using Sentinel 2 Images and Arc GIS Software
}

\author{
K. A. Chavan*, P. S. Bodake, C. B. Pande, A. A. Atre, S. D. Gorantiwar and A. D. Raut \\ Center for Advanced Agriculture Science and Technology for Climate-Smart Agriculture and \\ Water Management, MPKV, Rahuri, Maharashtra, India \\ *Corresponding author
}

\section{A B S T R A C T}

Ke y w o r d s
Cropping pattern,
NDVI, Arc Map,
Sentinel 2

Cropping pattern has undergone dramatic changes worldwide due to the eff ects of climate changes and human management activities. Cropping pattern is an major factor contributing to crop yield and food security at local, regional and national scales, and is a critical input data variable for many global climate, land surface, and crop models. Hence for creating annual cropping intensity maps at huge scales, MODIS images have difficulty with mixed land cover types within a pixel. Hence to generate cropping pattern maps over large spatial domains at high spatial resolution by Sentinel-2 time series image data for January 2019 using the Arc GIS software. In this pilot study, we report cropping pattern maps for January 2019 at spatial resolution over selected areas of Rahuri Tahsil. In this we compare area of selected village by using normalized diff erent vegetation index (NDVI) and by Supervised classification. In normalized diff erent vegetation index (NDVI) classification Kharif crop has highest area and in Supervised classification Soybean has highest area.

\section{Introduction}

Green revolution has made the country self dependent in meeting the food grain requirement of the population, but at the same time, also given birth to several new serious threats to sustain the existing level of production.

Cropping pattern is a basic component of cropping system. Cropping pattern is the proportion of an area undergoing various crops at a point with respect to space and time. Most of the Indian economy depends on agriculture. Indian agriculture mostly depends on Monsoons. As the monsoon is seasonal, agriculture production requires other water resource for crop production. Cropping pattern of an area is the manifestation of the climate, the soil, the facilities available like irrigation, fertilizer, mechanization etc. and the socio- economic factors. Due to the combined influences of global climate change, human activities and urbanization, cropping intensity has undergone dramatic changes worldwide. Cropland refers to all 
agricultural land, including permanently cultivated land, newly cultivated land, fallow land, and land in a grassland-farming rotation. In the context of solution of food problem of India, it becomes necessary to undertake suitable strategy to increase the production, per unit area per unit time because the expansion of area is very much limited and this country has reached the limit of physical frontiers in cultivation. Changes in cropping pattern are also caused in response to change in one or more of the same factors. However many times the socio-economic factors plays a dominant role for adopting a new cropping system and thereby neglecting the parameters essential for agro- ecological balance. The growth of agriculture is associated with a major shift in cropping pattern, high input use in terms of fertilizer, pesticide, water etc. (Grewal and Sidhu, 1990).

Now a day in agriculture, remote sensing techniques are widely used. Remote Sensing and GIS plays an key role in cost effective agricultural applications (Zhang and Hoffman, 2011). Remote sensing has been proven to be an potential tool for monitoring cropping practices. Remote sensing collects a huge data sets over a large area with regular observation. Remote sensing technology have demonstrated its potentiality in providing information of the characteristics and spatial distribution of nature resources including agriculture resources because of their unique advantage of providing multitemporal and multispectral resolution. Use of satellite remote sensing data has also provide to be more cost effective, reliable, timely and faster then the conventional ground based surveys of agricultural resources (Yedage et al.,).

Remote Sesing provides seasonal data which could be useful in agriculture. Satellite remote sensing technology due to its synoptic and repetitive coverage provides consistent and valuable information about the crop acreage and production at different spatial scales from global to local scales.

There are various indices for highlighting vegetation bearing areas on a remote sensing scene. NDVI is a common and widely used index (Bhandari and Kumar, 2012). It is an important vegetation index, largely applied in research on global environmental and climatic change. NDVI values increase with increase in soil wetness for same canopy coverage. NDVI image is useful because of its crop biomass, vigour and canopy cover (Son and Cru, 2012). NDVI value also varies with crop growth stages.

Landsat offers improved spatial resolution over MODIS, it may not be able to provide the necessary temporal resolution to identify cropping pattern. Sentinel-2 is an Earth observation mission by the European Union Copernicus Program that thoroughly receive optical imagery at high resolution. The mission is a constellation of two satellites that were launched in June 2015 (Sentinel-2a) and March 2017 (Sentinel-2b). Sentinel-2 sensors have spatial resolutions of 10,20 , and $60 \mathrm{~m}$, and include 13 bands in the visible, near infrared, and shortwave infrared part of the spectrum. The main objective of this study was to identify cropping pattern using Sentinel-2 data.

\section{Study area}

The study area of Khadambe budruk falls under Rahuri taluka under Ahmednagar district, Maharashtra, India as shown in Fig. 1. As the area is under semi arid climatic condition it is important to sustain the water resource. Rahuri is located at $19.38^{\circ} \mathrm{N}$ $74.65^{\circ} \mathrm{E}$.The average rainfall of the Rahuri taluka is $511 \mathrm{~mm}$. Cropping patterns play an major role in groundwater and surface water exploration. In Khadambe budruk majorly found Wheat, Gram, sugarcane and other 
horticulture crops. The total geographical area of village is 1027.22 hectares. Rahuri is nearest town to Khadambe $\mathrm{Bk}$ which is approximately $12 \mathrm{~km}$ away.

\section{Materials and Methods}

Sentinel 2 data is downloaded from the USGS (United State Geological Survey) Earth explorer website (earthexplorer.usgs.gov) and processed in Arc map 10.2 software. The data is processed under NDVI to extract the vegetation information. The NDVI is used to analyze the remote sensing measurements, and assess whether the object observed contains live green vegetation or not. NDVI Stands for Normal Difference Vegetative Index, which gives the vegetative proportions in an area. The formula to calculate NDVI is shown below.

$$
\text { NDVI }=(\text { NIR- Red }) /(\mathrm{NIR}+\mathrm{Red})
$$

where NIR is near infrared reflectance and RED is visible red reflectance. The wavelength range of NIR band is (750-1300 $\mathrm{nm})$ and Red band is $(600-700 \mathrm{~nm})$. The NDVI is motivated by the observation vegetation, which is the difference between the NIR and red band. It should be larger for greater chlorophyll density. The value of NDVI ranges from -1 to +1 . Very low value of NDVI ( 0.1 and below) correspond to barren areas of rock or sand. Moderate values represent grassland (0.2 to 0.3 ), while high value indicates temperate and tropical rainforests (0.6 to 0.8). Bare soil is represented with NDVI values closest to 0 and water bodies are represented with negative NDVI values. The degree of greenness is equal to the chlorophyll concentration. NDVI values vary with the reflection of infrared radiation by water-filled leaf cells and the absorption of red light by plant chlorophyll.
The data is recoded in Arc map software by taking training sets. The training set selections taken according to major crop production in the study area. Hence, the major crops Sugarcane, wheat, gram and soybean were taken into considerations. Later the crop type classifications were successfully achieved.

\section{Results and Discussion}

Cropping pattern analysis has been done using Sentinel 2 data from the USGS Earth explorer website. Using Arc map 10.2 software the area was calculated. The total extent of the study area is 1027.22 ha. As per crop pattern mapping by Supervised Classification (Table 1) 502.25 ha is covered by Soybean, 324.52 ha is covered by Forest/Non cropping land, 189.36 ha is covered by Sugarcane/Wheat, 10.94 ha is covered by Build-Up. Soil moisture is the major limiting factor affecting productivity of crops particularly under rainfed climatic condition. From these results it was clear that soybean covered highest area followed by Sugarcane/Wheat. Soyabean grown in sandy loam soil and required higher temperature for rapid growth.

The normalized difference vegetation index is used for estimating vegetation cover from satellite data. Moreover the created NDVI images could be used to identify cropping pattern. The NDVI differencing method is relatively easy to implement and simple to interpret cropping pattern. As per NDVI Classification (Table 2) there are six classes in which Kharif crop covered 262.32 ha., Forest/Non cropping land covered 175.03 ha, Sugarcane covered 168.82 ha, Sugarcane is a crop grown commonly in moderate to low rainfall areas, and on soils with a heavy texture (better moisture retaining capacity) but with good drainage. Gram crop covered 161.07 ha, Wheat crop covered 142.29 ha and Horticulture crop covered 117.56 ha (Fig. 2$7)$. 
Table.1 Area calculated by supervised classification

\begin{tabular}{|c|c|c|}
\hline Sr. No & Classes & Area(ha) \\
\hline $\mathbf{1 .}$ & Build-Up & 10.94 \\
\hline $\mathbf{2 .}$ & Forest/Non cropping land & 324.52 \\
\hline $\mathbf{3 .}$ & Soyabean & 502.25 \\
\hline $\mathbf{4 .}$ & Sugarcane/Wheat & 189.36 \\
\hline & Total & $\mathbf{1 0 2 7 . 0 7}$ \\
\hline
\end{tabular}

Table.2 Area calculated by NDVI classification

\begin{tabular}{|c|c|c|}
\hline Sr. No & Classes & Area(ha) \\
\hline $\mathbf{1 .}$ & Forest/Non cropping land & 175.03 \\
\hline $\mathbf{2 .}$ & Gram crop & 161.07 \\
\hline $\mathbf{3 .}$ & Horticulture crop & 117.56 \\
\hline $\mathbf{4 .}$ & Kharif crop & 262.32 \\
\hline $\mathbf{5 .}$ & Sugarcane & 168.82 \\
\hline $\mathbf{6 .}$ & Wheat crop & 142.29 \\
\hline & Total & $\mathbf{1 0 2 7 . 0 9}$ \\
\hline
\end{tabular}

Fig.1 Map of study area
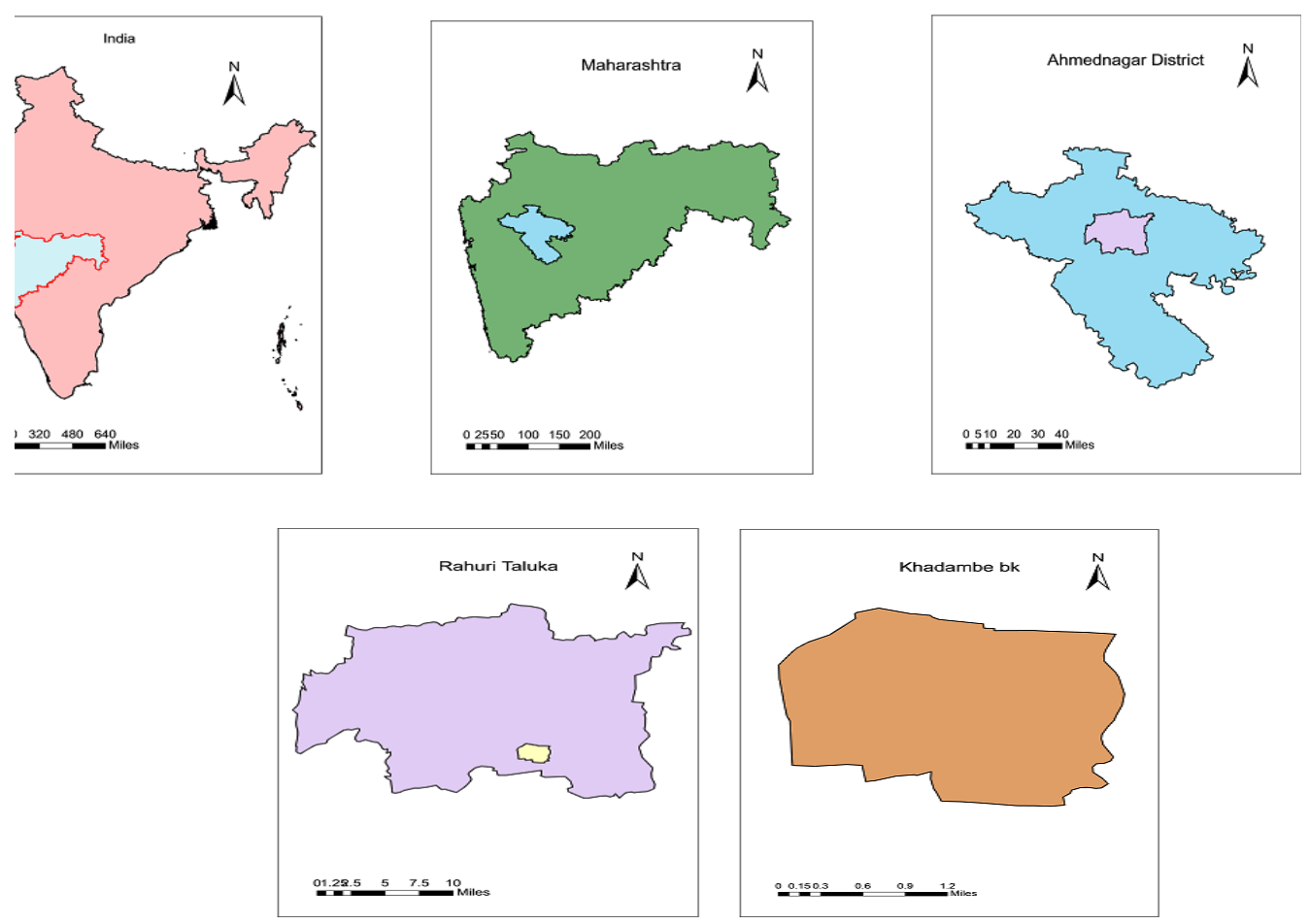
Fig.2 Flow chart of methodology used

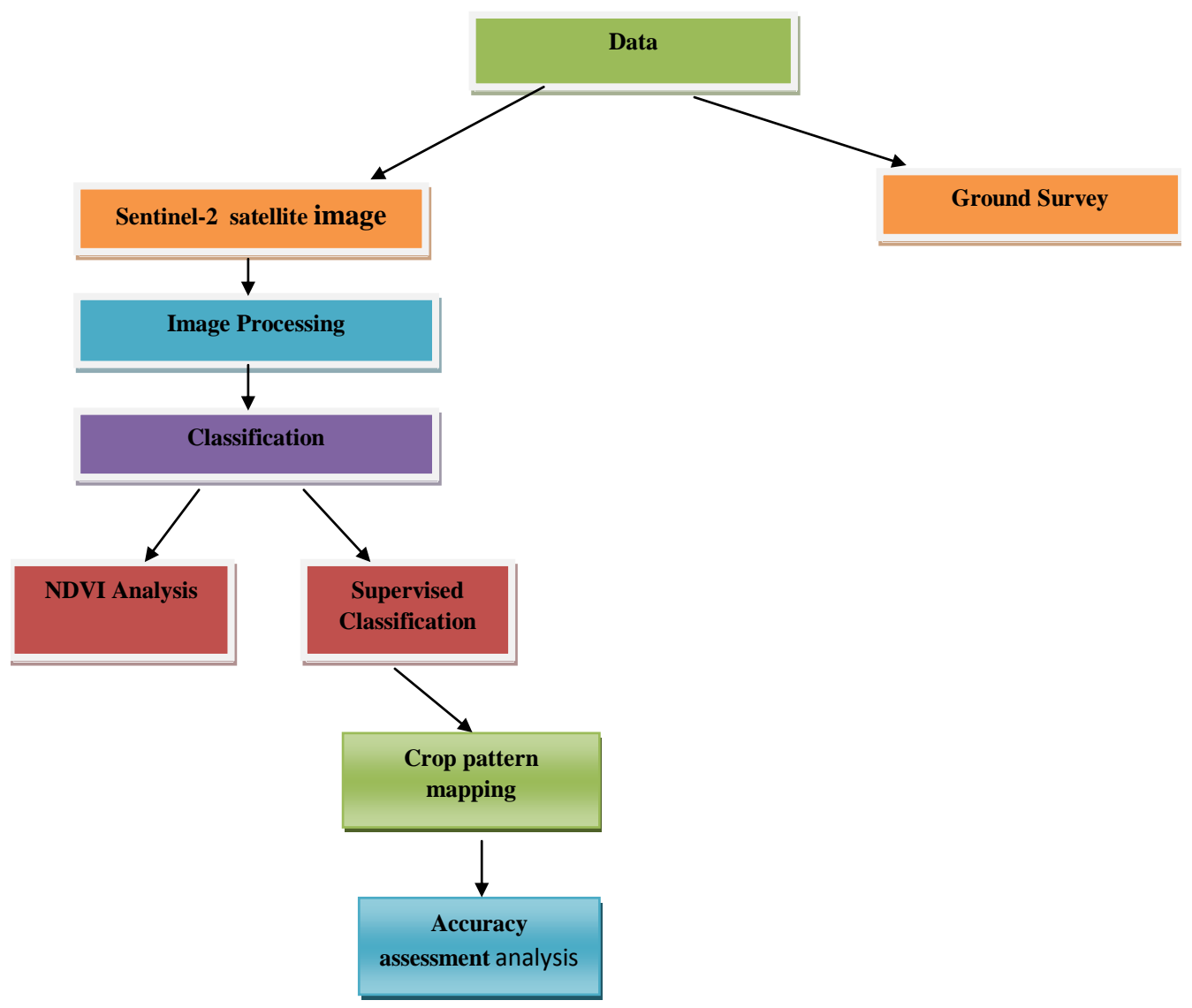

Fig.3 Map of study area

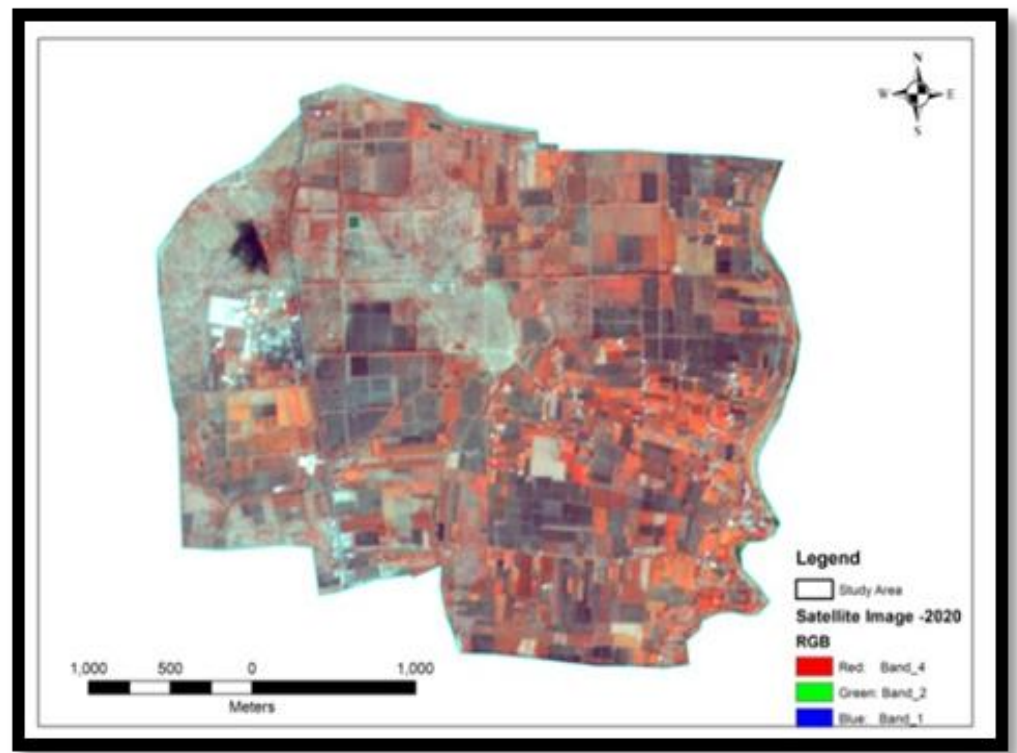


Fig.4 Cropping pattern map by supervised classification

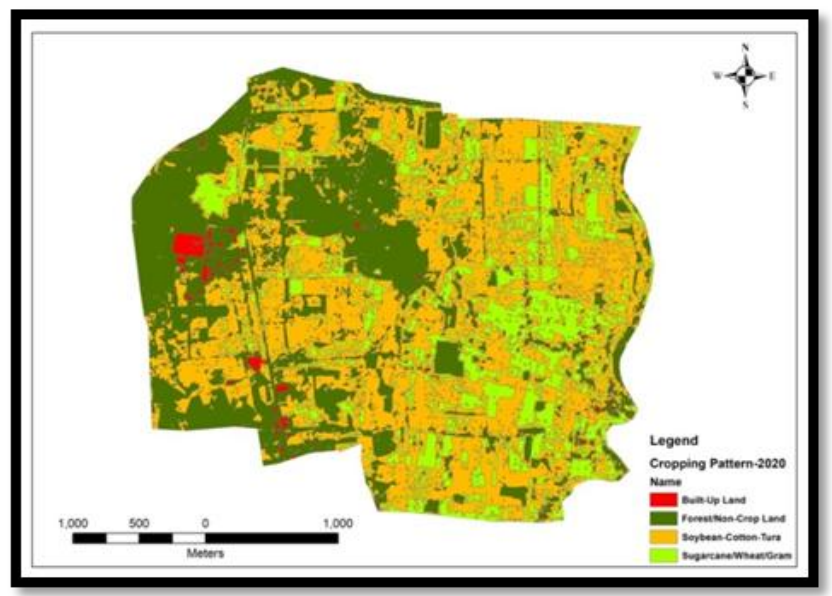

Fig.5 Cropping pattern map by NDVI classification

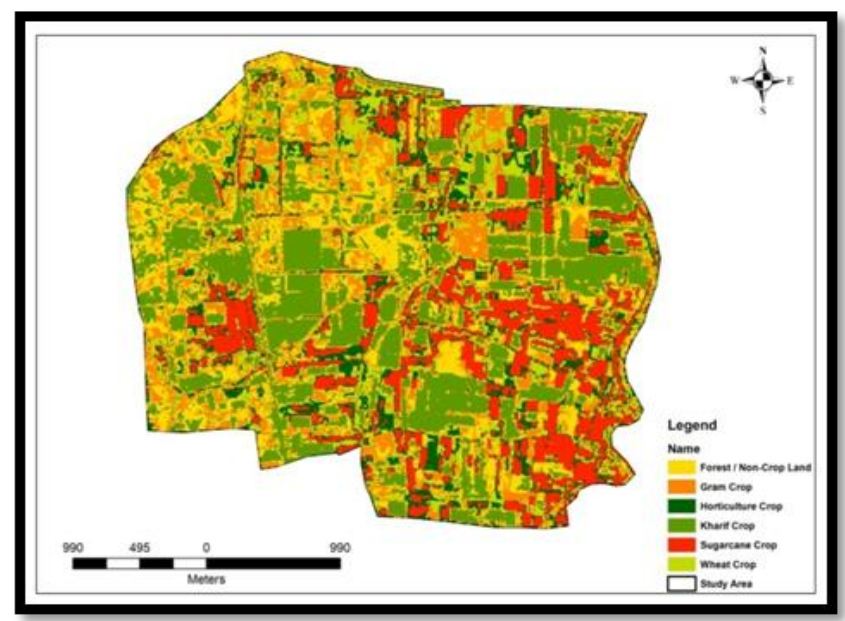

Fig.6 Cropping pattern map by supervised classification

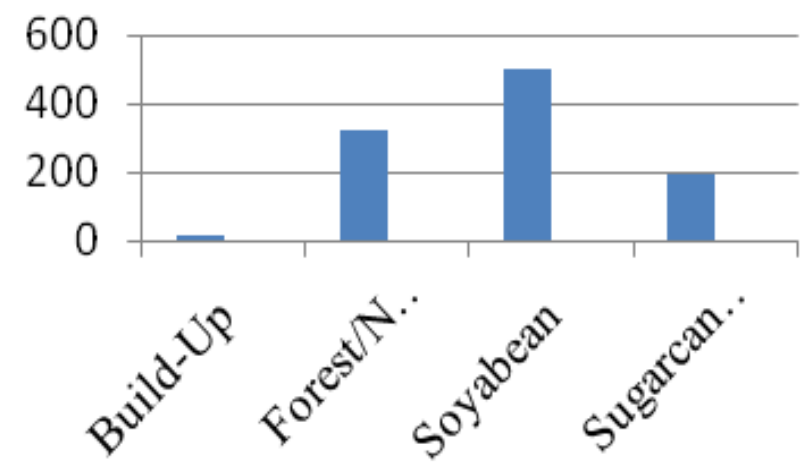


Fig.7 Cropping pattern Map by NDVI

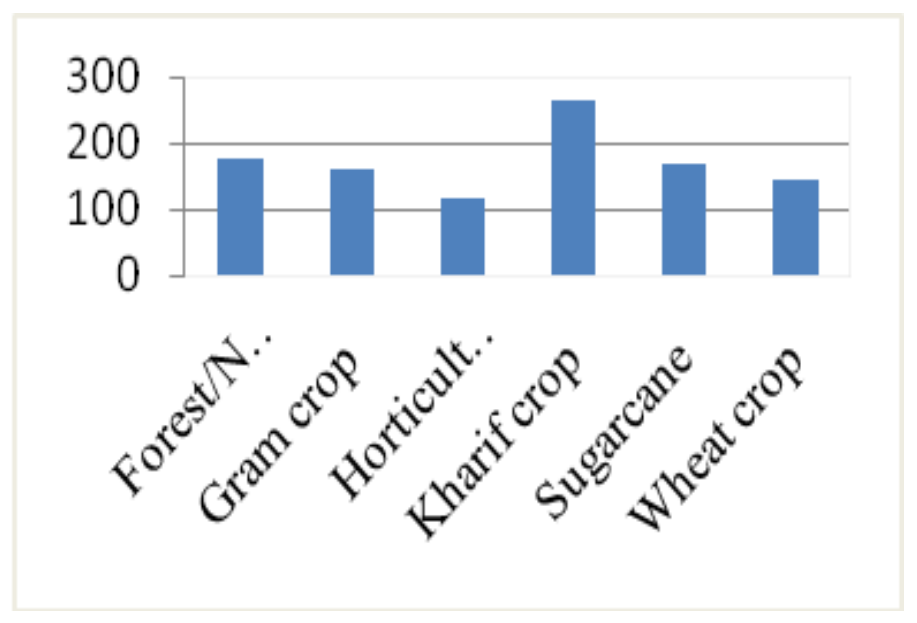

In conclusions the present study introduces a cropping pattern of the year January 2020 of the Khadambe budruk falls under Rahuri taluka under Ahmednagar district, Maharashtra using Sentinel 2 data downloaded from the USGS (United State Geological Survey) Earth explorer website (earthexplorer.usgs.gov) and processed in Arc map 10.2 software. Emerging technologies like Satellite remote sensing can be successfully used for deriving the spatial and temporal agricultural information. Such information which is generally not collected and maintained in any organised fashion in the conventional mechanisms is very useful for detecting cropping pattern. Moreover, the classification of satellite imagery data is a proper tool to derive cropping pattern.

Comparing between two classification provide the basis to proper cropping pattern of selected area. As per crop pattern mapping by Supervised Classification 502.25 ha is covered by Soybean followed by 324.52 ha is covered by Forest/Non cropping land. And by NDVI Classification there are six classes in which Kharif crop covered 262.32 ha. followed by Forest/Non cropping land covered 175.03 ha.

\section{Acknowledgment}

We are grateful towards Principal Investigator, Centre for Advance Agriculture Science and Technology on Climate-Smart Agriculture and Water Management, MPKV, Rahuri (Agricultural University) and ICAR, NAHEP and World Bank for providing the necessary facilities and financial support for conducting this research.

\section{References}

Grewal, S.S. and Sidhu, M.S. (1990). A study on Growth of Punjab Agriculture. Research Report, Department of Economics and Sociology, Punjab Agric. University, Ludhiana, India

Bhandari, A.K. and Kumar, A. (2012). "Feature Extraction using Normalized Difference Vegetation Index (NDVI): A Case Study of Jabalpur City". Procedia Technology. (6), 612- 621.

Son, N.T., Chen, C.F. and Cru, C.R. (2012). Mapping Major Cropping Patterns in Southeast Asia from Modis Data Using Wavelet Transform and Artificial Neural Networks. ISPRS- International Archives of the Photogrammetry, Remote Sensing and Spatial Information 
Sciences, $\quad X X X I X-B 3, \quad 421-425 . \quad$ Yedage, A.S., Gavali, R.S. and Patil, R.R. https://doi.org/10.5194/isprsarchivesxxxix-b3-421-2012.

Zhang, H., Lan, Y., Lacey, R., Hoffmann, W.C., Westbrook, J. K. (2011). Spatial (2013). Remote sensing and gis base crop acreage estimation of the sugarcane for Solapur district, Maharashtra, Golden analysis of NDVI readings with different Research Thoughts, Volume 2(11), 1-13. sampling densities. Transactions of the ASABE, 54(1), 349-354.

\section{How to cite this article:}

Chavan, K. A., P. S. Bodake, C. B. Pande, A. A. Atre, S. D. Gorantiwar and Raut, A. D. 2020. Identification of Cropping Pattern in Khadambe bk. using Sentinel 2 Images and Arc GIS Software. Int.J.Curr.Microbiol.App.Sci. 9(09): 1139-1145.

doi: https://doi.org/10.20546/ijcmas.2020.909.141 